\title{
Aerial Surveillance with Low-Altitude Long-Endurance Tethered Multirotor UAVs Using Photovoltaic Power Management System
}

\author{
Sunghun Jung ${ }^{1}\left(\mathbb{D}\right.$, Yonghyeon $\mathrm{Jo}^{2}$ and Young-Joon $\mathrm{Kim}^{3, *}$ \\ 1 Department of Electric Vehicle Engineering, Dongshin University, Jeollanam-do 58245, Korea; \\ jungx148@gmail.com \\ 2 Department of Energy Mechanical Facility, Dongshin University, Jeollanam-do 58245, Korea; \\ av1483110@gmail.com \\ 3 Department of Electronic Engineering, Gachon University, Gyeonggi-do 13120, Korea \\ * Correspondence: youngkim@gachon.ac.kr
}

Received: 28 January 2019; Accepted: 29 March 2019; Published: 6 April 2019

\begin{abstract}
For a continuous surveillance mission using a swarm of multiple tethered low-altitude long-endurance (LALE) multirotor-type unmanned aerial vehicles (UAVs), we developed a $500 \mathrm{~W}$ class photovoltaic power management system (PPMS) which monitors voltage and current flows of photovoltaic (PV) panels, battery pack, and UAV and controls power flows to support UAV flight operation. In contract to a fixed-wing UAV, a tethered multirotor UAV can generate continuously varying closed-circuit television (CCTV) like ground map images by stitching incoming images though the operation range is limited. With an indoor flight experiment, we demonstrated the usefulness of the PPMS and proved operation integrity. According to the results, a total of six multirotor UAVs were required to continuously perform a surveillance mission for $5 \mathrm{~h} 46 \mathrm{~min}$ from 11:04 to $16: 50$.
\end{abstract}

Keywords: low-altitude long-endurance (LALE); photovoltaic power management system (PPMS); unmanned aerial vehicle (UAV)

\section{Introduction}

Technologies related with low-altitude long-endurance (LALE), medium-altitude long-endurance (MALE), and high-altitude long-endurance (HALE) unmanned aerial vehicles (UAVs) have recently become crucial due to various desires, including, in particular, internet coverage extension to remote areas having no mobile network coverage [1].

In general, LALE, MALE, and HALE UAVs fly up to $3000 \mathrm{~m}$, between 3000 and $9000 \mathrm{~m}$, and over $9000 \mathrm{~m}$, separately, and flight time exponentially increases as operation altitude increases. HALE UAVs, for instance, are designed to fly, in theory, indefinitely without any energy source from outside aside from solar power or fuel-cell based on a hydrogen generator. Although MALE and HALE UAVs have advantages in the sense of flight time and energy efficiency, the size of wingspan is too large to safely operate in an urban area, and the runway is indispensable. Thus, despite the limited flight time, light and small LALE UAVs, instead, are more preferable to safely and freely use in civilian areas complying with legal regulations.

Research related to UAV energy efficiency optimization is summarized in Reference [2]. According to Reference [2], research trends to optimize UAV energy efficiency can be categorized into mainly three: (1) Mission waypoint optimization (MWO), (2) hybrid-electric propulsion systems (HEPS), and (3) effective power management systems (EPMS). Among these, the present paper particularly focuses on HEPS. 
There have been several research level attempts to develop a small LALE UAV based on a HEPS using a fuel cell (FC), solar cell, and battery pack. Gang and et al. developed a $380 \mathrm{~W}$ class LALE HEPS UAV based on a power-switching technique to control power flows from two sources using solid-state relays [3]. Lee and et al. developed a $200 \mathrm{~W}$ class LALE HEPS UAV using an active power management system (PMS), in which the active PMS limits boundaries of each energy source to maintain a target state of charge (SOC) of the battery pack [4]. Stroman and et al. developed a $1200 \mathrm{~W}$ class LALE HEPS UAV which particularly adopts soaring and optimal path planning techniques to extend the flight range [5]. Chen and et al. developed a $500 \mathrm{~W}$ class LALE HEPS UAV design and proved the system validity using MATLAB/Simulink based simulation [6].

There is also a research branch developing only a solar cell based LALE UAV. Shiau and et al. developed a $60 \mathrm{~W}$ class electric propulsion system only using a solar cell and also developed three main systems, including maximum power point tracking (MPPT), a battery management system (BMS), and a power conversion system $[7,8]$.

Both methods, using the combination of a FC, solar cell, and battery pack or using the combination of solar cell and battery pack, require using a power management system (PMS) to control power flows. Belvedere and et al. developed an experimental real-time operable PMS and tested it using a photovoltaic (PV) module emulator and a load emulator [9]. According to the results, the PMS successfully maintained the SOC of a battery pack to be around $50 \%$ and the voltage of a battery pack to be between predefined $\mathrm{V}_{\text {batt,nom }}^{\min }$ and $\mathrm{V}_{\text {batt,nom }}^{\max }$. However, Belvedere and et al. used constant set values for both the PV module emulator and load emulator and so, we cannot determine whether the PMS will behave well, even in a dynamically changing environment. In addition, load C-rates used in two test cases were less than $1 \mathrm{C}$, and this is not adequate for the multirotor UAV application which uses dozens of C-rates. Kranjec and et al. developed a PMS to control power flows between PV modules, a battery pack, and a brushless direct current (DC) machine, but they only passively controlled by managing the duty cycle of a transistor attached near the PV modules rather than controlling all power sources [10].

Most of the abovementioned studies tried to build a fixed-wing type LALE UAV which uses stationary alternating current (AC) loads and requires a long runway and a large area to operate. From this perspective, we designed the tethered multirotor-type LALE UAV swarming system for, ultimately, the continuous aerial surveillance without any single human intervention using pure solar energy. Compared to the fixed-wing UAV, the multirotor-type UAV results in much higher magnitude and fluctuation of current and voltage, and the handling technique of this dynamic energy flow is very important to develop the long-endurance multirotor-type UAV.

A swarm of small multirotor-type LALE UAVs could generate continuously varying closed-circuit television (CCTV) like ground map images by stitching incoming images to the existing ground map image. Although the operation range is limited, a tethered multirotor-type LALE UAV could hover for several hours in the air and perform a continuous surveillance mission for the specific area.

The flow of this paper is as follows. In Section 2, the overall concept of the aerial surveillance mission is described. In Section 3, equations for the SOC-based flight time estimation are derived. In Section 4, equation derivation for choosing the optimum number of UAVs is performed. In Section 5 , the concept and specification of the photovoltaic power management system (PPMS) are explained. In Section 6, the current patterns of both PV panels and UAV achieved from the outdoor experiment are presented. In Section 7, the indoor charge-discharge experiment setup and results using profiles obtained from the previous section are explained. Finally, Section 8 contains the conclusion of this paper and future works.

\section{Aerial Surveillance}

If we assume that the UAV carries a camera having the $\alpha$ angle of field of view (FOV), it could monitor the area calculated by:

$$
R=h \tan \frac{\alpha}{2}
$$


where $h$ is the altitude of the UAV (m) and $R$ is the radius of the monitored area (m).

Our purpose here is to continuously observe the area of interest using multiple UAVs flying above the $h$ altitude, so we assume that more than two homogeneous UAVs are available for the mission. We decided to operate multiple UAVs rather than increasing the amount of battery pack capacity, since the continuous operation of UAV might lead to failures of the motor, bearing, etc. Monitoring the battery pack SOC of each UAV is necessary for the success of the continuous surveillance mission. Monitoring the state of power (SOP) and state of health $(\mathrm{SOH})$ is excluded since those are out of range.

Overall, the conceptual diagram of the aerial surveillance operation is shown in Figure 1. Multiple UAVs are used for the continuous surveillance mission. Each UAV is powered from the PPMS, which controls powers from two sources, including PV panels and a battery pack. Only one UAV hovers at the preassigned altitude at a time to minimize the total energy consumption. While one UAV hovers, the other UAVs are charged during the daytime (Figure 1a). When the UAV1 consumes most of its battery pack energy, it lands on the ground and the UAV2 takes off (Figure 1b). While UAV2 hovers for the surveillance mission, the UAV1 keeps charging the battery pack for the next takeoff flight (Figure $1 \mathrm{c}, \mathrm{d}$ ). During the night, all UAVs stay on the ground, since there is no sunlight. When the sun rises at dawn, all UAVs are charged and start the surveillance mission again.

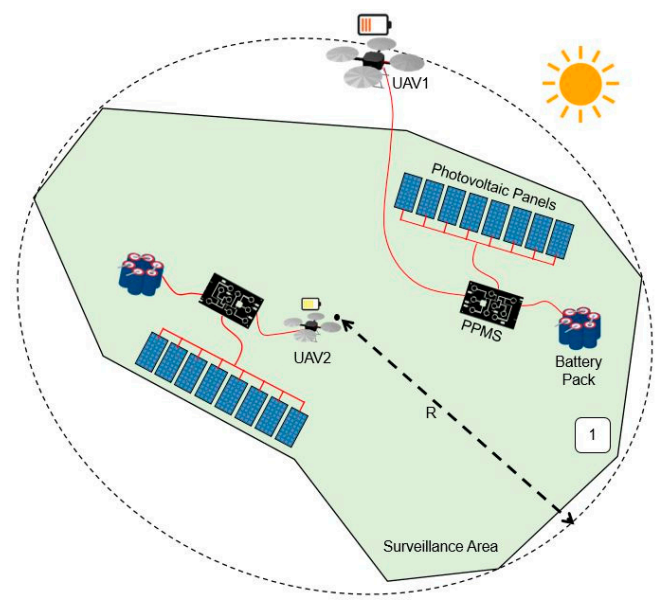

(a)

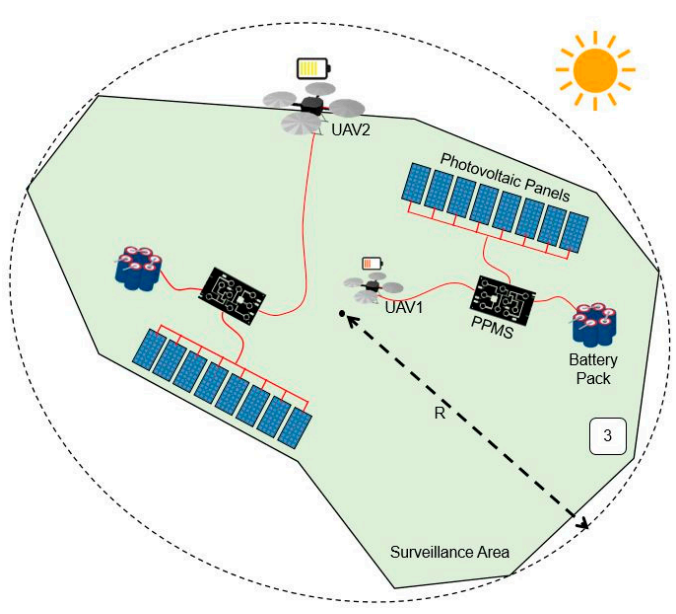

(c)

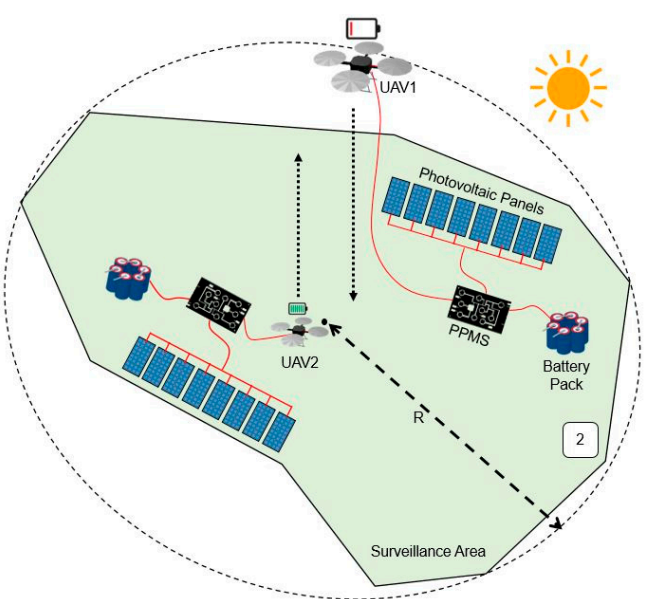

(b)

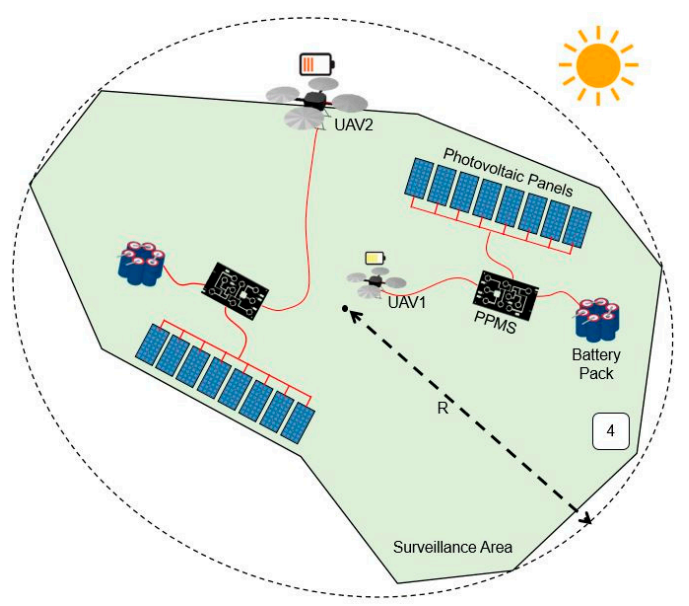

(d)

Figure 1. Step-by-step scenario of the aerial surveillance operation: (a) Step 1, (b) step 2, (c) step 3, and $(\mathbf{d})$ step 4. 


\section{SOC and Flight Time Estimation}

Detailed information regarding the method of SOC calculation can be found in Reference [11]; therefore, it is excluded from this paper. With the SOC value calculated from Reference [11], we can draw a trace of SOC by calculating:

$$
c_{s o c}=100-r_{\text {dis, takeoff }} t_{\text {dis, takeoff }}-r_{\text {dis, hover }} t_{\text {dis, hover }}-r_{\text {dis,land }} t_{\text {dis, land }}+r_{c h} t_{c h}
$$

where $c_{s o c}$ is the current $\mathrm{SOC}(\%), r_{\text {dis,takeoff }}$ is the discharging rate during the takeoff flight operation $(\% / s), r_{\text {dis, hover }}$ is the discharging rate during the hovering flight operation $(\% / s), r_{\text {dis,land }}$ is the discharging rate during the landing flight operation $(\% / \mathrm{s}), r_{c h}$ is the charging rate during the battery pack charging operation $(\% / \mathrm{s}), t_{\text {dis, takeoff }}$ is the time taken during the takeoff flight operation (s), $t_{d i s, \text { hover }}$ is the time taken during the hovering flight operation $(\mathrm{s}), t_{\text {dis, land }}$ is the time taken during the landing flight operation (s), and $t_{c h}$ is the time is taken during the battery pack charging operation (s). Here, the discharging rate, $r$, can be calculated as $r=\frac{d z}{d t}$, where $z$ is the SOC (\%).

Since takeoff and landing operations take a relatively short time and require much less energy compared to the hovering operation, we could simplify Equation (2) as:

$$
c_{s o c}=100-r_{\text {dis, hover }} t_{d i s, h o v e r}+r_{c h} t_{c h} .
$$

Here, we can calculate $r_{d i s, h o v e r}$ and $r_{c h}$ by dividing the SOC-time curve into three sections and calculating the slope of each section as shown in Figure 2.

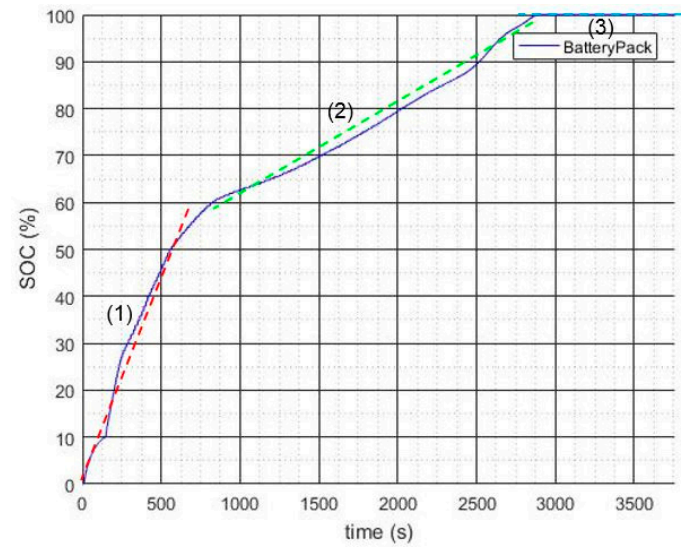

(a)

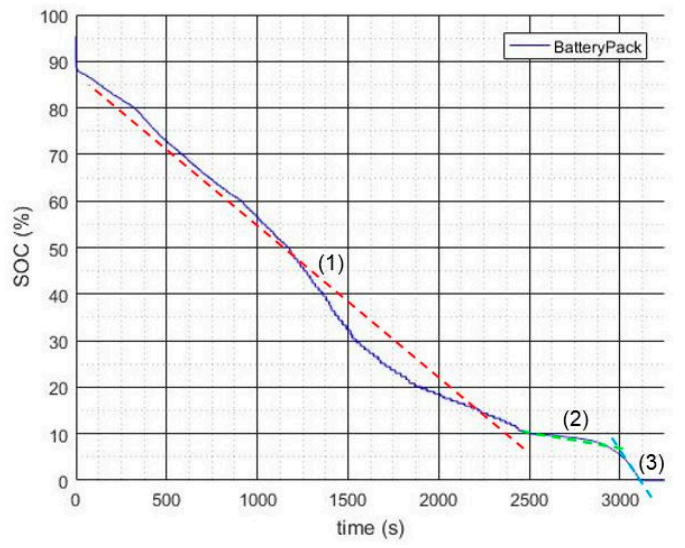

(b)

Figure 2. State of charge (SOC)-time curve obtained using a 3.3 Ah 4S1P Li-Po battery pack using a $1 \mathrm{C}$ charging and discharging current pattern: (a) Charging curve and (b) discharging curve.

\section{UAV Number Optimization}

To optimize the minimum number of required UAVs for the continuous surveillance mission, we set two assumptions: (1) Homogeneous multirotor-type UAVs are used, and (2) the UAV could perform surveillance mission only when it hovers.

To calculate the minimum number of required UAVs to continuously monitor the surveillance area, we need to solve:

$$
\begin{aligned}
& \text { minimize } m \\
& \text { subject to }\left[\frac{t_{c h}^{i}}{t_{\text {dis,hover }}^{i-1}}+1\right] \leq m, \\
& \text { for } i=\{2,3, \cdots, n\}
\end{aligned}
$$

where $m$ is the number of UAVs (ea) and $n$ is the chronological order of flight performed during a day (h). The order of flight during a day matters since the charging and discharging rate varies depends on the $n$. 


\section{PPMS}

The operation concept of power transmission during a day is shown in Figure 3, and the overall PPMS specifications and configuration are shown in Table 1 and Figure 4. There are three main power connectors connected to the PV panels, battery pack, and UAV and the current and voltage of all three main power connectors are monitored and shown in the liquid crystal display (LCD) module (voltage and current data of PV panels, battery pack, and UAV, progress time, battery pack charging power, and battery pack temperature from the top line).

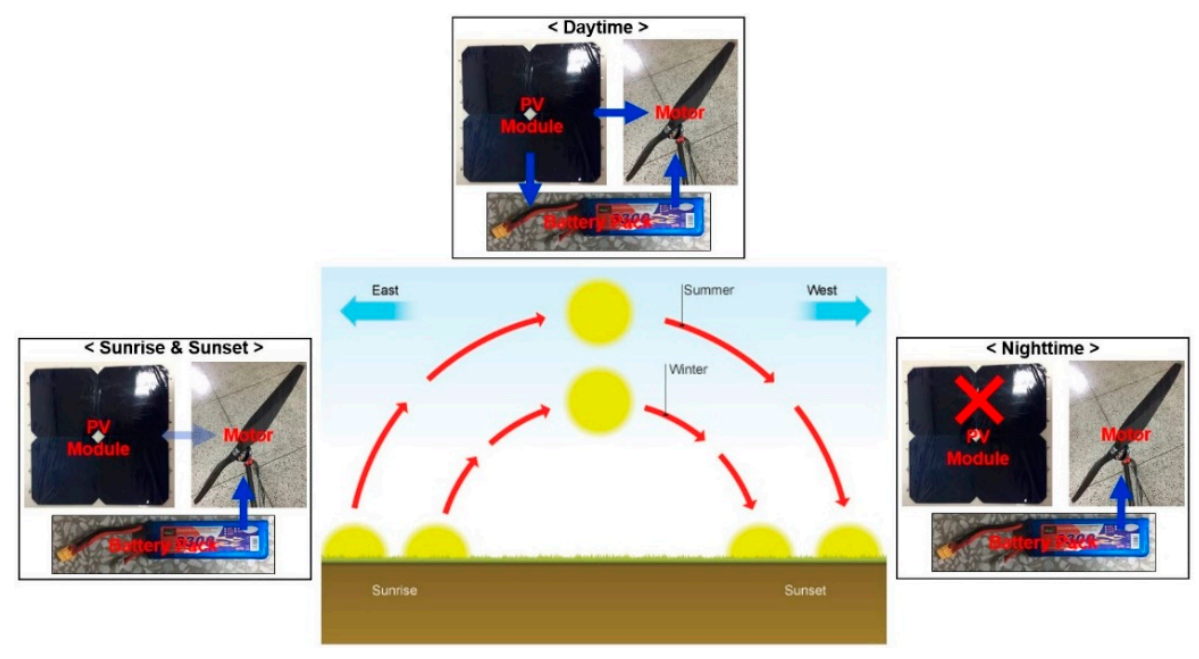

Figure 3. Operation concept of power transmission during a day.

Table 1. Specifications of the photovoltaic power management system (PPMS).

\begin{tabular}{cc}
\hline & Specification \\
\hline MCU & Arduino Mega 2560 \\
Storage & Transcend 2 GB SD card \\
Current Sensor & Blkbox 100A Bi AC/DC Current Sensor \\
Voltage Sensor & In-House Development \\
Temperature Sensor & TI LM35 Precision Centigrade Temperature Sensor \\
\hline
\end{tabular}

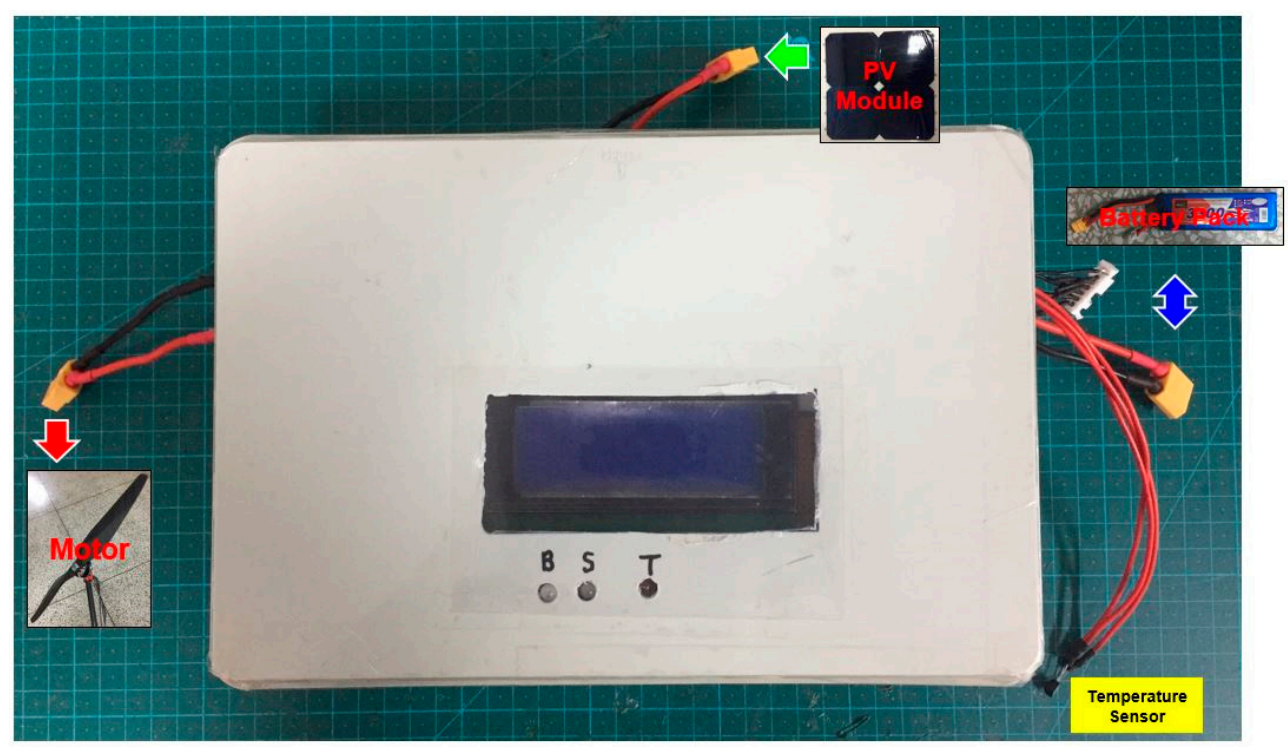

Figure 4. The hardware of the PPMS. 
A conceptual diagram of the PPMS is shown in Figure 5. Four metal-oxide-semiconductor field-effect transistors (MOSFETs) labeled as a solar switch, battery switch, battery drone switch, and drone switch are used to open and close the power flow. Three diodes are used to prevent the inverse current flow. Three current sensors and three voltage sensors are used to monitor both current and voltage variations occurring at three main power sources.

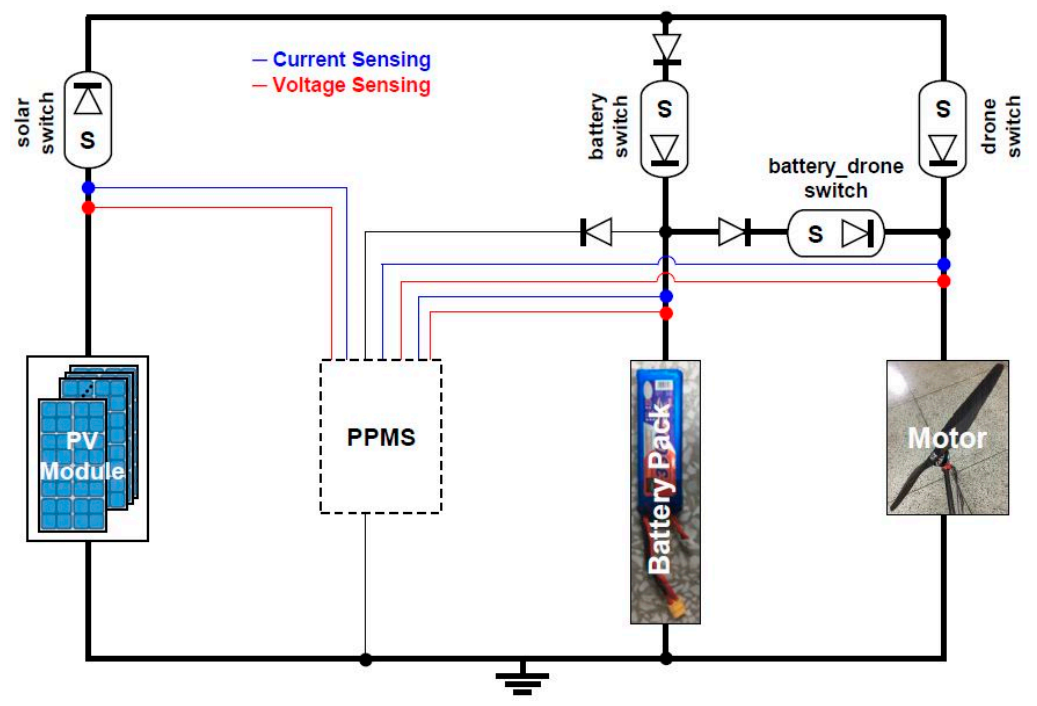

Figure 5. Conceptual diagram of the PPMS.

Charging current flow to charge the battery pack should be properly managed to prevent battery pack swelling or to avoid overly slow charging time. The amount of charging current could be managed by varying the MOSFET (labeled as the battery switch in Figure 4) duty cycle. Since we are using a 3.3 Ah battery pack, we limited the charging current to be between 0 to 5 A by varying the duty cycle from 0 to 255. In Figure 6, Bat_vol_max is the maximum battery pack charging voltage which is set as $17.2 \mathrm{~V}$, Bat_vol is the current battery pack voltage, Tar_cur is the target charging current, Bat_vol_bulk is the battery pack voltage at which constant voltage (CV) mode starts, which is set as 16.8 V, Bat_cur is the current battery pack charging current, and duty is the duty cycle.

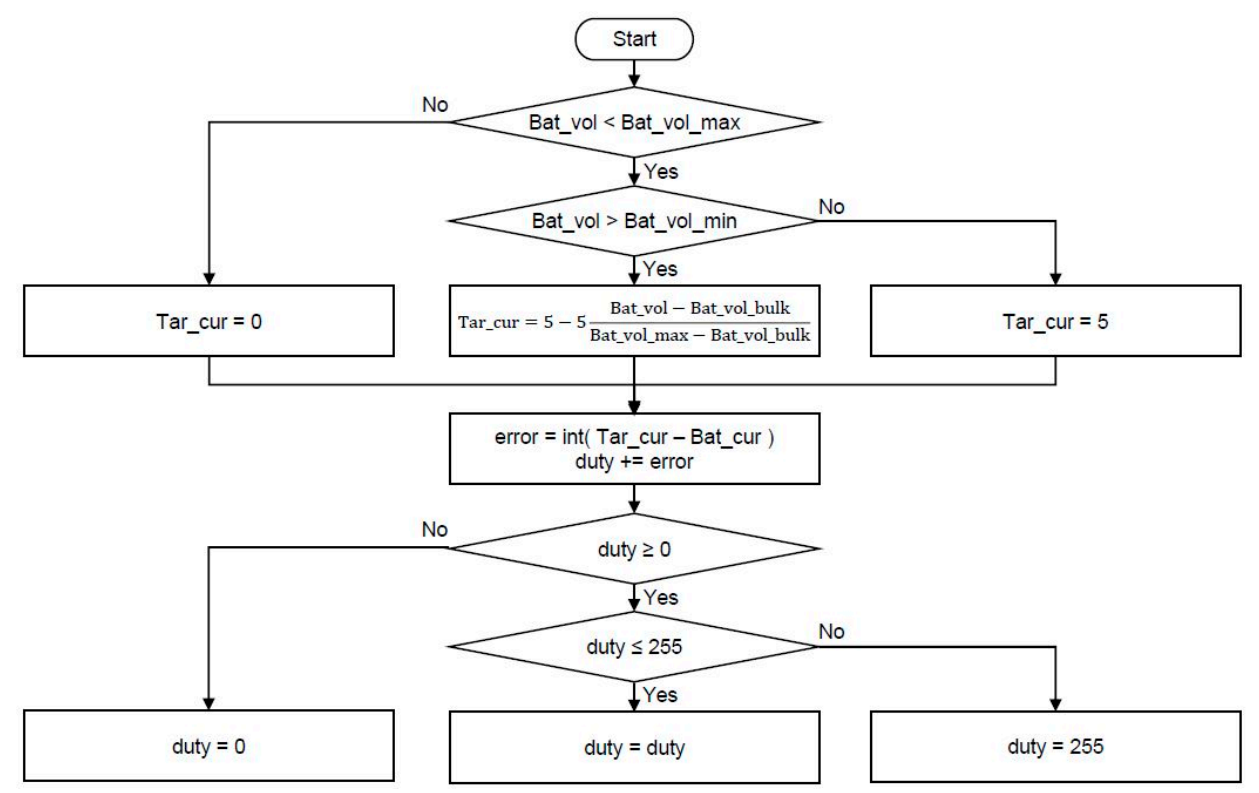

Figure 6. The software of the photovoltaic power management system. 


\section{Current Profiles of PV Panels and UAV}

The current profiles of the PV panels and UAVs were obtained (Figure 7) by performing outdoor experiments at the Dongshin University schoolyard on 11 January 2019 for $10 \mathrm{~h}$ from 08:00 to 18:00 (Figure 8). The current profile of PV panels was obtained using a PV power recording system (PPRS) as shown in Table 2 and Figure 9a. To monitor the current profile of UAV, the eLogger V4 module was used as shown in Figure 9b.

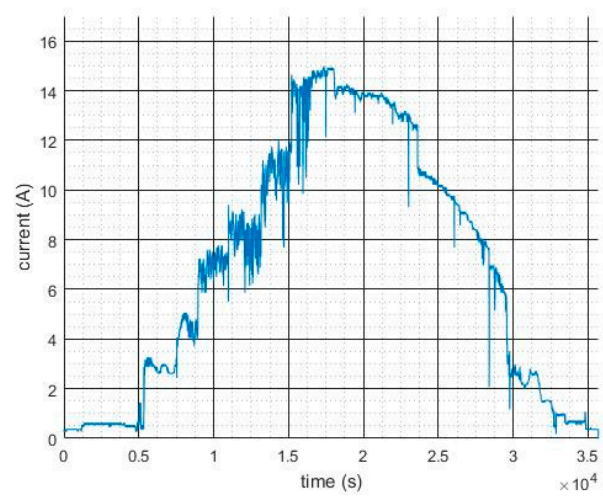

(a)

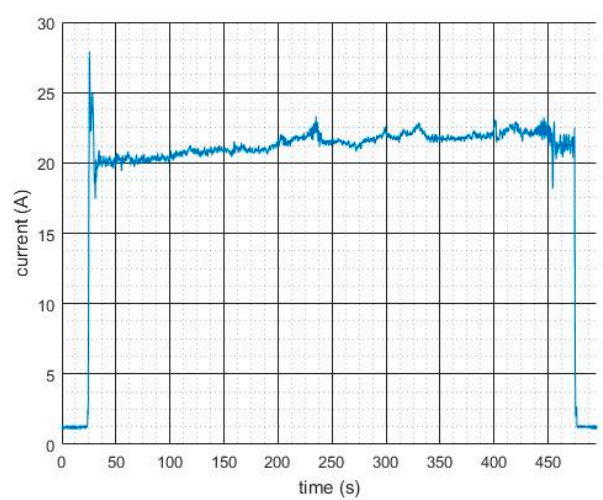

(b)

Figure 7. Current profile of PV panels and unmanned UAVs: (a) PV panels and (b) UAVs.

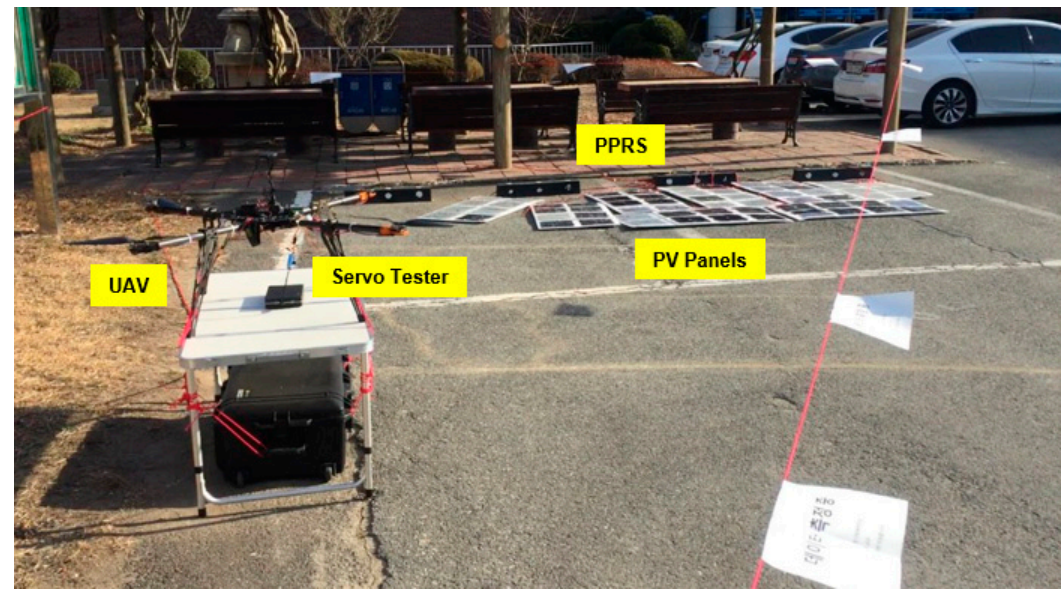

(a)
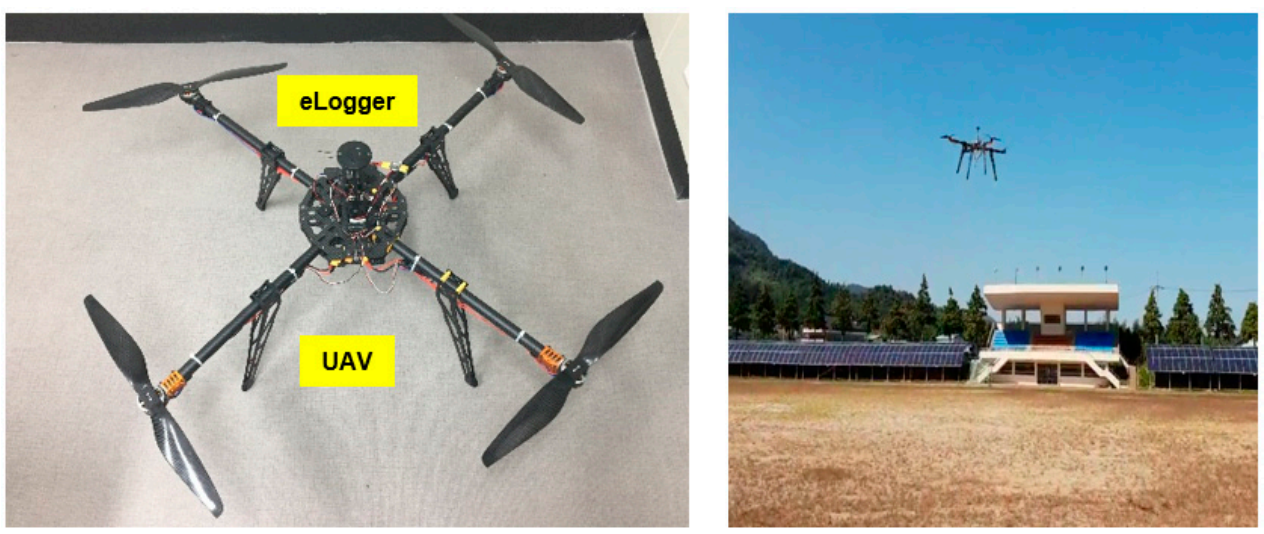

(b)

Figure 8. Outdoor experiments of PV panels and UAVs: (a) PV panels and (b) UAVs. 
Table 2. Specifications of the PPRS.

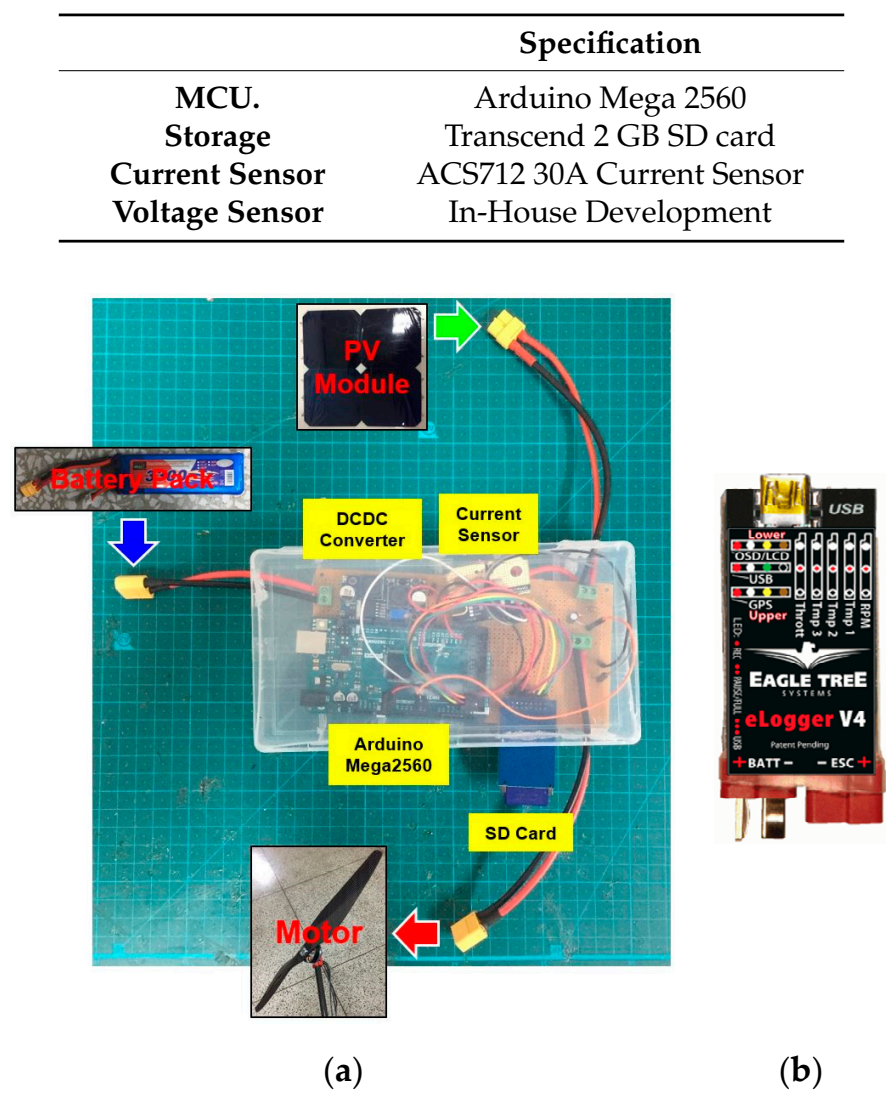

Figure 9. Hardware of the PPRS and eLogger V4: (a) PPRS and (b) eLogger V4.

The required current of the UAV with a varying throttle percentage is shown in Figure 10. According to Figures $7 \mathrm{~b}$ and 10, the UAV turns out to use about $60 \%$ of throttle percentage during hovering flight mode.

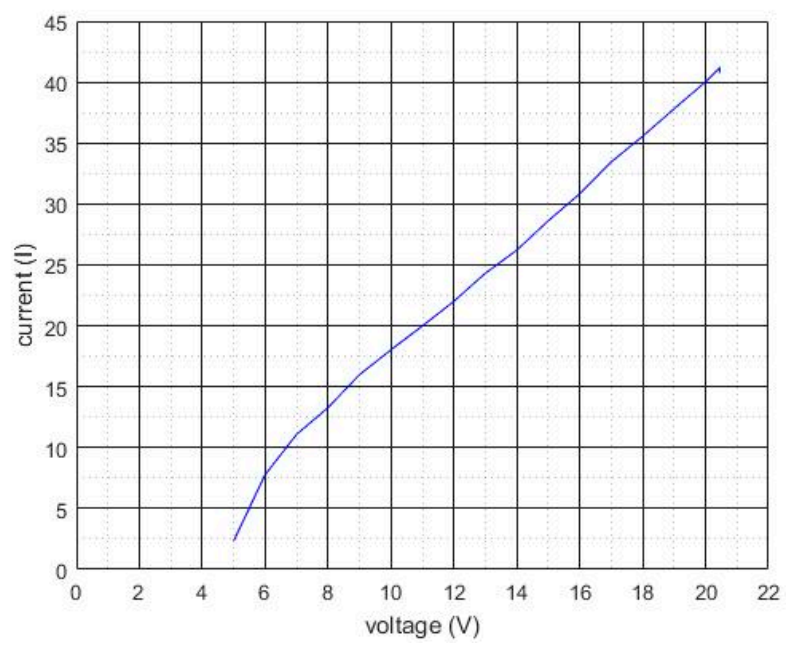

Figure 10. Current profile with varying throttle percentage of the UAV.

Specifications of the PV cell, UAV, and battery pack used for the outdoor experiment are listed in Tables $3-5$. In particular, we connected PV cells in the $32 \mathrm{~S} 8 \mathrm{P}$ array. 
Table 3. Specifications of the PV cell.

\begin{tabular}{cc}
\hline Item & Specification \\
\hline Max Voltage & $0.55 \mathrm{~V}$ \\
Max Current & $5.8 \mathrm{~A}$ \\
Max Power & $3.19 \mathrm{~W}$ \\
Efficiency & $20.8 \%$ \\
Size & $125 \mathrm{~mm} \times 125 \mathrm{~mm}$ \\
Weight & $6 \mathrm{~g}$ \\
\hline
\end{tabular}

Table 4. Specifications of the UAV.

\begin{tabular}{cc}
\hline Item & Specification \\
\hline Diagonal Wheelbase & $1150 \mathrm{~mm}$ \\
Dimension & $1660 \mathrm{~mm} \times 1660 \mathrm{~mm} \times 565 \mathrm{~mm}$ \\
Weight (w/o battery) & $2.26 \mathrm{~kg}$ \\
\hline
\end{tabular}

Table 5. Specifications of the battery pack.

\begin{tabular}{cc}
\hline Item & Specification \\
\hline Rated Capacity & $3300 \mathrm{~m} / \mathrm{Ah}$ \\
Nominal Voltage & $14.8 \mathrm{~V}$ \\
Configuration & $4 \mathrm{~S} 1 \mathrm{P}$ \\
Weight & $340 \mathrm{~g}$ \\
\hline
\end{tabular}

\section{Indoor Charge-Discharge Experiment}

\subsection{Experiment Setup}

Conceptual diagrams of the indoor charge-discharge experiment and the overall experiment setup are shown in Figures 11 and 12. Here, DC power supply supplies power by simulating the current profile of the PV panels as shown in Figure 7a. Electronic load discharges by simulating the current profile of the UAV as shown in Figure $7 \mathrm{~b}$. In particular, we extracted only the hovering discharging part from Figure $7 \mathrm{~b}$ and continuously repeated the hovering discharging current pattern.

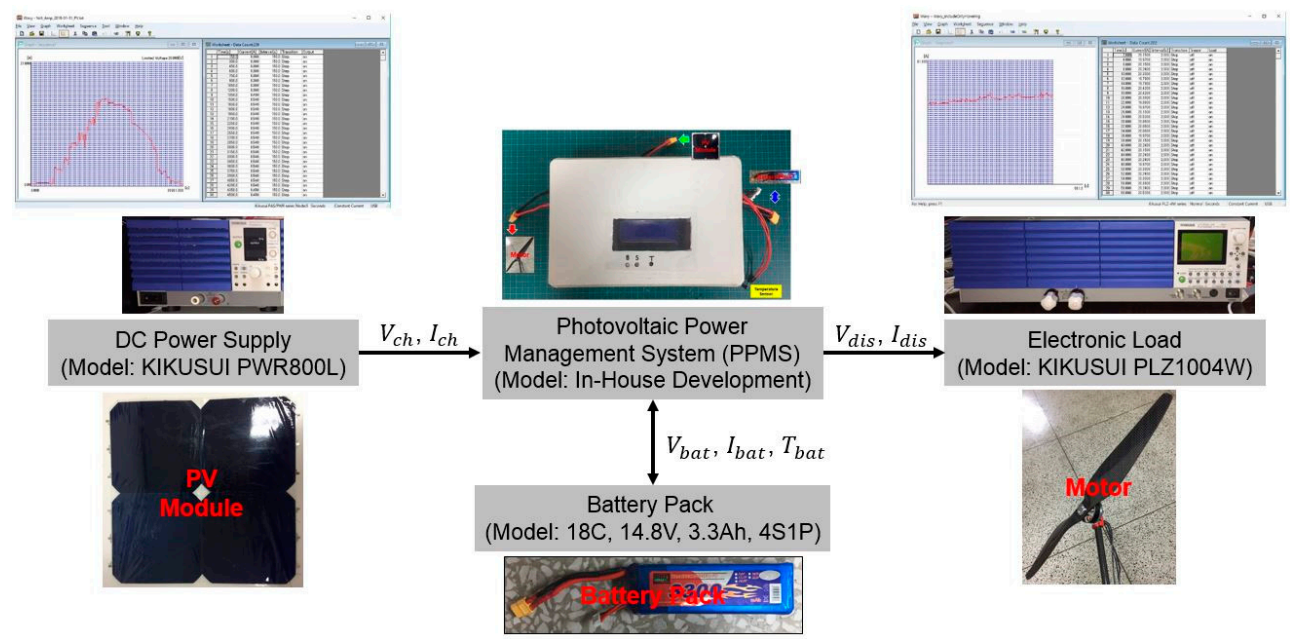

Figure 11. Conceptual diagram of the experiment. 

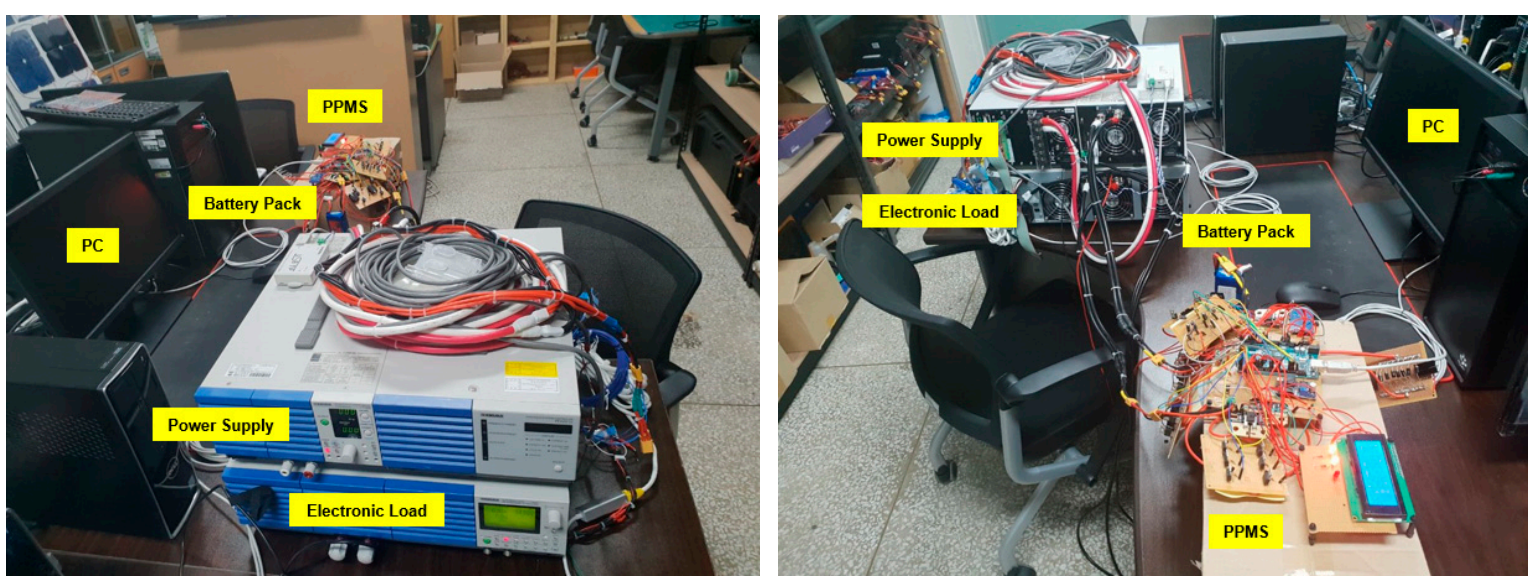

Figure 12. Experiment setup.

During the $10 \mathrm{~h}$ of the charge-discharge experiment, we assumed that the UAV takes off when the battery pack voltage becomes $17.1 \mathrm{~V}$ and lands when the battery pack voltage becomes $13.2 \mathrm{~V}$.

\subsection{Experiment Result}

The current, voltage, and SOC profiles during $10 \mathrm{~h}$ of the charge-discharge experiment are shown in Figure 13. Here, green color represents PV, blue color represents battery pack, and red color represents UAV. The SOC profile of the battery pack was calculated using the coulomb counting method.

According to the results shown in Figure 13, Table 6, Table 7, and Table 8, the UAV could perform a total of five flights from 10,247 s to 30,582 s with purely solar energy. We excluded the last flight performed at 35,972 s since the flight was performed not with a fully charged battery pack. Here, we calculated the charging vs. discharging time efficiency as $E=\frac{\text { discharging time }}{\text { charging time }}$.

Table 6. Charging progress time and rate of five flights.

\begin{tabular}{|c|c|c|c|c|c|}
\hline Flight Ordert & $\begin{array}{l}\text { Charging } \\
\text { Time (s) }\end{array}$ & $\begin{array}{c}\text { Charging } \\
\text { Rate } 1(\% / s)\end{array}$ & $\begin{array}{c}\text { Charging } \\
\text { Rate } 2(\% / s)\end{array}$ & $\begin{array}{c}\text { Charging } \\
\text { Rate } 3(\% / s)\end{array}$ & $\begin{array}{c}\text { Average Charging } \\
\text { Rate }(\% / \mathrm{s})\end{array}$ \\
\hline $\begin{array}{c}\text { 1st Flight } \\
\text { (Start: } 0 \text { s or } 08: 00) \\
\text { (End: } 10,247 \text { s or } 10: 51)\end{array}$ & 10,247 & 0.0826 & 0.0151 & 0 & 0.0098 \\
\hline $\begin{array}{c}\text { 2nd Flight } \\
\text { (Start: } 11,044 \mathrm{~s} \text { or } 11: 04) \\
\text { (End: } 14,866 \mathrm{~s} \text { or } 12: 08)\end{array}$ & 3822 & 0.1040 & 0.0229 & 0 & 0.0261 \\
\hline $\begin{array}{c}\text { 3rd Flight } \\
\text { (Start: } 16,136 \mathrm{~s} \text { or } 12: 29) \\
\text { (End: } 19,993 \mathrm{~s} \text { or } 13: 33)\end{array}$ & 3857 & 0.1077 & 0.0223 & 0 & 0.0259 \\
\hline $\begin{array}{c}\text { 4th Flight } \\
\text { (Start: } 21,474 \mathrm{~s} \text { or } 13: 58) \\
\text { (End: } 25,243 \mathrm{~s} \text { or } 15: 01 \text { ) }\end{array}$ & 3769 & 0.0938 & 0.0213 & 0 & 0.0265 \\
\hline $\begin{array}{c}\text { 5th Flight } \\
\text { (Start: } 26,235 \text { s or } 15: 17 \text { ) } \\
\text { (End: } 29,983 \text { s or } 16: 20 \text { ) }\end{array}$ & 3748 & 0.1019 & 0.0223 & 0 & 0.0267 \\
\hline
\end{tabular}



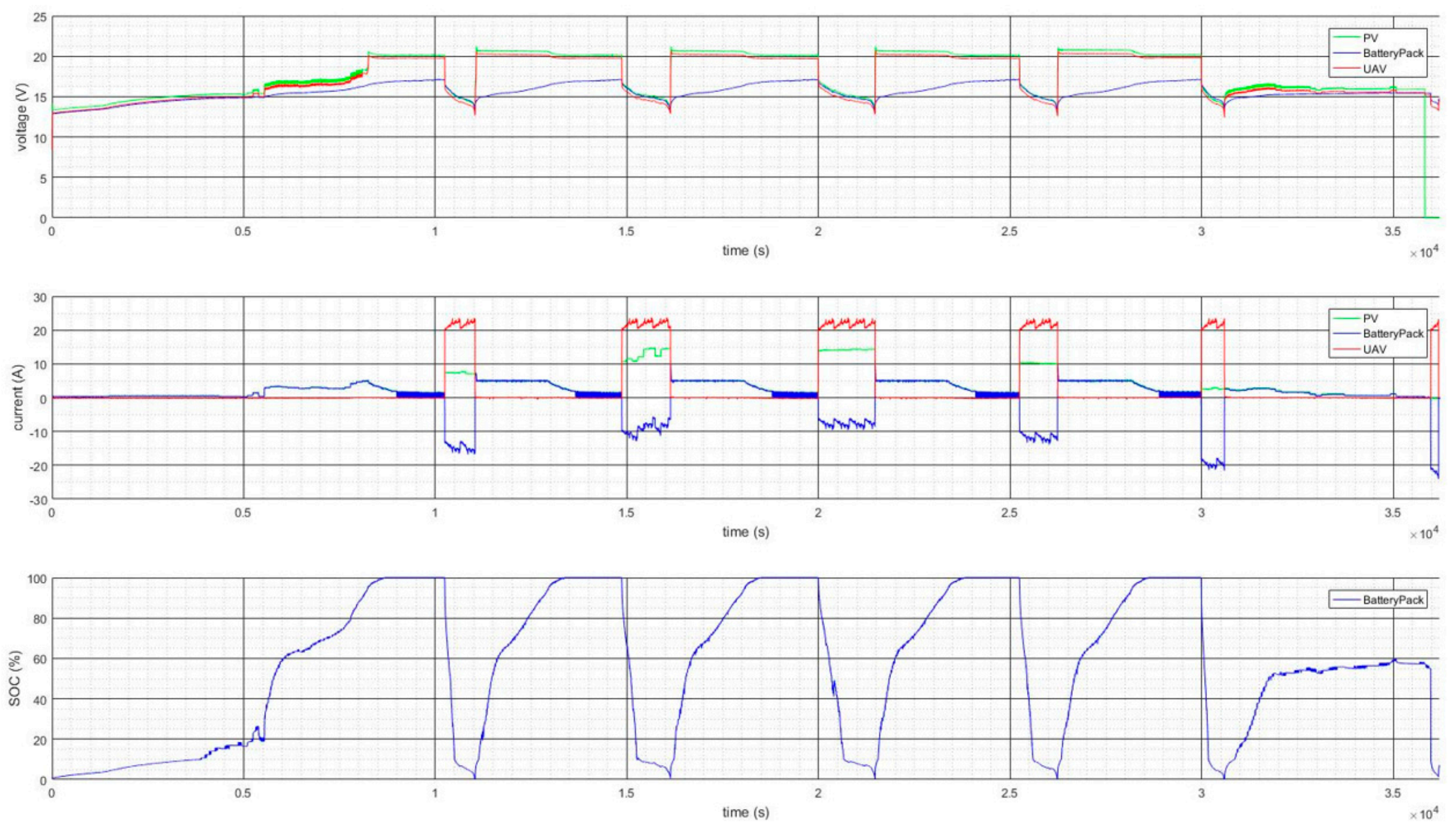

Figure 13. Experimental result. 
Table 7. Discharging progress time and rate of five flights.

\begin{tabular}{cccccc}
\hline Flight Order & $\begin{array}{c}\text { Discharging } \\
\text { Time (s) }\end{array}$ & $\begin{array}{c}\text { Discharging } \\
\text { Rate 1 (\%/s) }\end{array}$ & $\begin{array}{c}\text { Discharging } \\
\text { Rate 2 (\%/s) }\end{array}$ & $\begin{array}{c}\text { Discharging } \\
\text { Rate 3 (\%/s) }\end{array}$ & $\begin{array}{c}\text { Average Discharging } \\
\text { Rate (\%/s) }\end{array}$ \\
\hline $\begin{array}{c}\text { 1st Flight } \\
\text { (Start: 10,247 s or 10:51) } \\
\text { (End: 11,044 s or 11:04) }\end{array}$ & 797 & -0.3557 & -0.0146 & -0.0771 & -0.1255 \\
\hline $\begin{array}{c}\text { 2nd Flight } \\
\text { (Start: 14,866 s or 12:08) } \\
\text { (End: 16136 s 12:29) }\end{array}$ & 1270 & -0.2278 & -0.0054 & -0.0400 & -0.0787 \\
\hline $\begin{array}{c}\text { 3rd Flight } \\
\text { (Start: 19,993 s or 13:33) } \\
\text { (End: 21,474 s or 13:58) }\end{array}$ & 1481 & -0.1364 & -0.0054 & -0.0554 & -0.0675 \\
\hline $\begin{array}{c}\text { 4th Flight } \\
\text { (Start: 25,243 s or 15:01) } \\
\text { (End: 26,235 s 15:17) }\end{array}$ & 992 & -0.2571 & -0.0093 & -0.0526 & -0.1008 \\
\hline $\begin{array}{c}\text { 5th Flight } \\
\text { (Start: 29,983 s 16:20) }\end{array}$ & 610 & -0.4787 & -0.0193 & -0.0638 & -0.1639 \\
(End: 30593 s or 16:30) & & & & & \\
\hline
\end{tabular}

Table 8. Charging vs. discharging time efficiency.

\begin{tabular}{|c|c|}
\hline Flight Order & Efficiency $(\%)$ \\
\hline $\begin{array}{c}\text { 1st Flight } \\
\text { (Start: 0 s or 08:00) } \\
\text { (End: } 11,044 \text { s or } 11: 04)\end{array}$ & 7.7779 \\
\hline $\begin{array}{l}\text { 2nd Flight } \\
\text { (Start: } 11,044 \text { s or } 11: 04 \text { ) } \\
\text { (End: } 16,136 \mathrm{~s} \text { or } 12: 29)\end{array}$ & 33.2287 \\
\hline $\begin{array}{l}\text { 3rd Flight } \\
\text { (Start: } 16,136 \mathrm{~s} \text { or } 12: 29 \text { ) } \\
\text { (End: } 21,474 \mathrm{~s} \text { or } 13: 58 \text { ) }\end{array}$ & 38.3977 \\
\hline $\begin{array}{l}\text { 4th Flight } \\
\text { (Start: } 21,474 \text { s or } 13: 58) \\
\text { (End: } 26,235 \text { s or } 15: 17 \text { ) }\end{array}$ & 26.3200 \\
\hline $\begin{array}{l}\text { 5th Flight } \\
\text { (Start: } 26,235 \text { s or } 15: 17) \\
\text { (End: } 30,593 \text { s or } 16: 30)\end{array}$ & 16.2753 \\
\hline
\end{tabular}

According to the result shown in Table 8, the 3rd flight had the biggest efficiency value, which means that the discharging time was the largest and the charging time the smallest. It is indeed true, since there is the most sunshine during noon, resulting in the decreased charging time and, at the same time, the increased discharging time.

From the above results, the minimum number of UAVs required to perform continuous surveillance from 10,247 s (10:51) can be calculated by referring to Equation (4) and Table 9. The minimum number of UAVs turns out to be 6 to perform continuous surveillance from $11,044 \mathrm{~s}$ (11:04) to $31,813 \mathrm{~s}$ (16:50), and the total continuous flight time is $5 \mathrm{~h} 46 \mathrm{~min}$. 
Table 9. Minimum required a number of UAVs for continuous surveillance.

\begin{tabular}{|c|c|c|}
\hline Flight Order & \multicolumn{2}{|c|}{ Required Number of UAVs } \\
\hline $\begin{array}{l}\text { 2nd Flight } \\
\text { (Start: } 11,044 \text { s or } 11: 04 \text { ) } \\
\text { (End: } 16,136 \text { s or } 12: 29 \text { ) }\end{array}$ & $\left\lceil\frac{t_{c h}^{2}}{t_{\text {dis, hover }}^{1}}+1\right\rceil$ & $\leq m=6$ \\
\hline $\begin{array}{l}\text { 3rd Flight } \\
\text { (Start: } 16,136 \text { s or } 12: 29) \\
\text { (End: } 21,474 \text { s or } 13: 58)\end{array}$ & $\left\lceil\frac{t_{c h}^{3}}{t_{\text {dis, hover }}^{2}}+1\right\rceil$ & $\leq m=4$ \\
\hline $\begin{array}{l}\text { 4th Flight } \\
\text { (Start: } 21,474 \text { s or } 13: 58) \\
\text { (End: } 26,235 \text { s or } 15: 17 \text { ) }\end{array}$ & $\left\lceil\frac{t_{c h}^{4}}{t_{d i s, h o v e r}^{3}}+1\right\rceil$ & $\leq m=3$ \\
\hline $\begin{array}{l}\text { 5th Flight } \\
\text { (Start: } 26,235 \text { s or } 15: 17) \\
\text { (End: } 30,593 \text { s or } 16: 30)\end{array}$ & $\left\lceil\frac{t_{c h}^{5}}{t_{d i s, h o v e r}^{4}}+1\right\rceil$ & $\leq m=4$ \\
\hline
\end{tabular}

\section{Conclusions}

The PPMS uses the ATmega328-based Arduino microcontroller, which monitors the voltage/current of eight PV panels, battery pack, and UAV and displays data on the ground control station (GCS). The PPMS controls the PV power and battery pack power to support UAV flight operation. We performed an indoor flight experiment to demonstrate the usefulness of the PPMS and proved the operation integrity of the PPMS. According to the results, at least $6 \mathrm{UAVs}$ were required for a continuous surveillance mission for $5 \mathrm{~h} 46 \mathrm{~min}$ from 11:04 to 16:50.

In the future, we plan to miniaturize the PPMS to weigh much less so it could be mounted on the UAV. Further, for the autonomous takeoff and landing flight operations, we will develop Gazebo flight simulator-based software in the loop simulation (SILS) and hardware in the loop simulation (HILS).

Author Contributions: S.J. created the models, developed the methodology, designed computer programs, conducted research and the investigation process, wrote the initial draft, edited the initial draft, and led responsibility for the research activity planning; Y.J. designed computer programs; Y.-J.K. reviewed the manuscript, synthesized the study data, and supervised the research activity. All authors read and approved the manuscript.

Funding: This research was funded by the National Research Foundation of Korea (2017R1C1B5018040) and by the Gachon University Research Fund of 2018 (GCU-2018-0294).

Conflicts of Interest: The authors declare no conflict of interest.

\section{References}

1. Facebook's Huge Internet Drone with Wingspan of a 737 Completes Its Second Flight Over Arizona. Available online: https:/ / goo.gl/Fg2dDL (accessed on 27 January 2019).

2. Amoiralis, E.I.; Tsili, M.A.; Spathopoulos, V.; Hatziefremidis, A. Energy Efficiency Optimization in UAVs: A review. Mater. Sci. Forum 2014, 792, 281-286. [CrossRef]

3. Gang, B.; Kwon, S. Design of an Energy Management Technique for High Endurance Unmanned Aerial Vehicles Powered by Fuel and Solar Cell Systems. Int. J. Hydrog. Energy 2018, 43, 9787-9796. [CrossRef]

4. Lee, B.; Kwon, S.; Park, P.; Kim, K. Active Power Management System for an Unmanned Aerial Vehicle Powered by Solar Cells, a Fuel Cell, and Batteries. IEEE Trans. Aerosp. Electron. Syst. 2014, 50, 3167-3177. [CrossRef]

5. Stroman, R.O.; Edwards, D.J.; Jenkins, P.; Carter, S.; Newton, D.; Kelly, M.; Heinzen, S.; Young, T.; Dovrokhodov, V.; Langelaan, J.; et al. The Hybrid Tiger: A Long Endurance Solar/Fuel Cell/Soaring Unmanned Aerial Vehicle. In Proceedings of the 48th Power Sources Conference, Denver, CO, USA, 11-14 June 2018.

6. Chen, H.; Khaligh, A. Hybrid Energy Storage System for Unmanned Aerial Vehicle (UAV). In Proceedings of the 36th Annual Conference on IEEE Industrial Electronics Society, Glendale, AR, USA, 7 November 2010. 
7. Shiau, J.K.; Ma, D.M. Development of an Experimental Solar-Powered Unmanned Aerial Vehicle. J. Chin. Inst. Eng. 2015, 38, 1-13. [CrossRef]

8. Shiau, J.K.; Ma, D.M.; Yang, P.Y.; Wang, G.F.; Gong, J.H. Design of a Solar Power Management System for an Experimental UAV. IEEE Trans. Aerosp. Electron. Syst. 2009, 45, 1350-1360. [CrossRef]

9. Belvedere, B.; Bianchi, M.; Borghetti, A.; Nucci, C.A.; Paolone, M.; Peretto, A. A Microcontroller-Based Power Management System for Standalone Microgrids with Hybrid Power Supply. IEEE Trans. Sustain. Energy 2012, 3, 422-431. [CrossRef]

10. Kranjec, B.; Sladic, S.; Giernacki, W.; Bulic, N. PV System Design and Flight Efficiency Considerations for Fixed-Wing Radio-Controlled Aircraft-A Case Study. Energies 2018, 11, 2648. [CrossRef]

11. Jung, S.; Jeong, H. Extended Kalman Filter-Based State of Charge and State of Power Estimation Algorithm for Unmanned Aerial Vehicle Li-Po Battery Pack. Energies 2017, 10, 1237. [CrossRef]

(C) 2019 by the authors. Licensee MDPI, Basel, Switzerland. This article is an open access article distributed under the terms and conditions of the Creative Commons Attribution (CC BY) license (http://creativecommons.org/licenses/by/4.0/). 